\title{
NEW WASTE PROGNOSTIC AND WASTE MANAGEMENT SYSTEM ASSESSMENT TOOLS: EXAMPLES OF IMPLEMENTATION FOR MUNICIPALITIES IN THE COUNTRIES WITH RAPID GROWING ECONOMIES
}

\author{
Gintaras Denafas ${ }^{l}$ \\ Ingrida Rimaityte ${ }^{I}$ \\ Viktoras Racys ${ }^{I}$ \\ Iwona Mackow ${ }^{2}$ \\ Wojciech Gornikowskt ${ }^{2}$ \\ Ryszard Szpadt ${ }^{2}$ \\ Marta Sebastijan ${ }^{2}$ \\ Konstantinia Tsilemou ${ }^{3}$ \\ Demetrios Panagiotakopoulos ${ }^{3}$ \\ Katarina Jankowicova ${ }^{4}$ \\ Oskar Cermak ${ }^{4}$ \\ Francese Giralt \\ Josepa Garreta ${ }^{5}$ \\ Sandra Coloms \\ Elena Sune \\ Eva Ma Garcia ${ }^{5}$ \\ ${ }^{I}$ Kaunas University of Technology, Lithuania \\ ${ }^{2}$ Wroclaw University of Technology, Poland \\ ${ }^{3}$ Democritus University of Thrace, Greece \\ 'Slovak University of Technology, Slovakia \\ ${ }^{s}$ University Rovira I Virgili, Spain
}

\begin{abstract}
This paper compiles results of the research project 'The Use of Life Cycle Assessment Tools for the Development of Integrated Waste Management Strategies for Cities and Regions with Rapid Growing Economies', in short: LCA-IWM (for more: www.lca-iwm.net). The project, which runs from September 2002 until August 2005, is financially supported by the European Commission. It is part of the Fifth Framework Programme.
\end{abstract}




\author{
Kalmar ECO-TECH '05 and \\ The Second Baltic Symposium on Environmental Chemistry \\ KALMAR, SWEDEN, November 28-30, 2005
}

Some municipal waste management scenarios for Kaunas (Lithuania), Wroclaw (Poland), Xanthi (Greece), Nitra (Slovakia) and Reus (Spain) was created and assessed to compare impact on environmental, economical and social sustainability. The chosen waste management scenarios can be understood like stepped evolution of waste management system, i.e. the next scenarios is an extension of previous scenario. The first scenarios for every city correspond to the situation in the current waste management systems, the next scenarios include not only landfilling, but also increased rates of separate collection, mechanical-biological pre-treatment and incineration.

At the Conclusion the best Scenarios regarding environmental and economical sustainability is pointed.

\title{
KEYWORDS
}

Life Cycle Assessment; Assessment tool; Municipal waste management; Waste treatment; Mechanical-biological pre-treatment; Waste incineration

\section{INTRODUCTION}

This article compiles the results of the research project 'The Use of Life Cycle Assessment Tools for the Development of Integrated Waste Management Strategies for Cities and Regions with Rapid Growing Economies', in short: LCA-IWM. The project, which ran from September 2002 until August 2005, was financially supported by the European Commission. It is part of the Fifth Framework Programme.

The results of the LCA-IWM project consist of two decision support tools: a Waste Prognostic Tool and a Municipal Solid Waste Management S ystem (MSWMS) Assessment Tool (also called: LCA-IWM Assessment Tool). The Prognostic Tool enables the prediction of future amounts of generated waste based on a limited amount of input parameters. These parameters consist of the current amount and composition of household waste and predictions of some general socio-economic indicators on the one hand and historical data on these factors on the other (available in the tool). The Assessment Tool enables the planning and assessment of waste management strategies. Up to four different scenarios can be created and compared. Each scenario, apart from general user inputs, consists of three basic waste management sub-systems:

- Temporary Storage

- Collection and Transport

- Treatment, Disposal \& Recycling

For all scenarios the environmental, economic and social impacts can be determined, providing a sustainability assessment of the various alternatives.

Four to five alternative waste management scenarios, reflecting various situations and predictions of the waste management were developed for five European cities (Xanthi (Greece), Kaunas (Lithuania), Wroclaw (Poland), Nitra (Slovakia), Reus (Spain)) in close collaboration with the local municipality representatives (see Figure 1). One scenario (generally No. 1 but in Reus No. 3) characterises the present situation, while the other three or four analyse some possible developments (characterised by different solutions of Temporary Storage, Collection, Transport 
and Treatment). Obviously, there are also many other potential alternatives in each case, not presented here, which should be assessed using developed tools in order to find the best solution. Presented results of case studies show the wide range of different potential solutions and demonstrate possibilities of the tools to assess them [1].

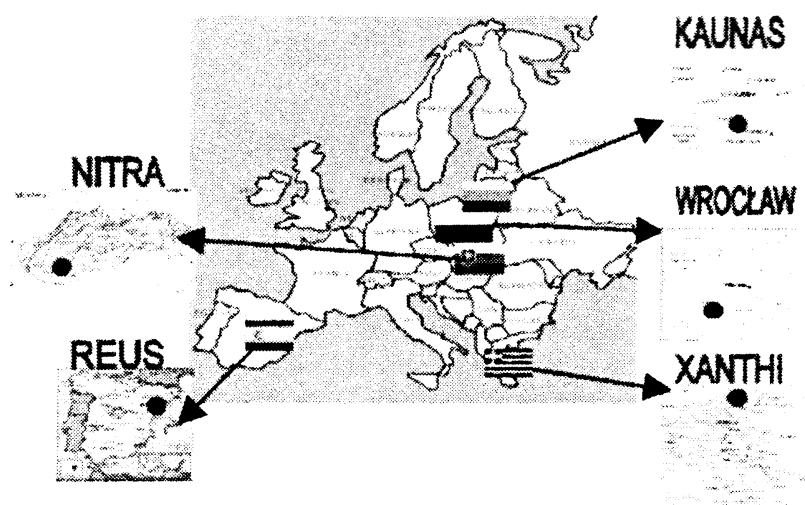

Figure 1. Locations of cities.

\section{BASIC WASTE MANAGEMENT SUB-SYSTEMS}

Temporary Storage is the point where household waste leaves the household and enters the waste management system. The waste is temporarily stored in bins, containers and sacks prior to collection.

The direct impacts of this stage contain the:

- environmental emissions due to emissions of bin and sack production,

- the total economic costs of this stage as well as

- a set of social impacts with regard to the social acceptability and social equity of the waste management system.

Collection and Transport includes the:

- collection of unseparated and separated solid waste and recyclables in an urban area, and

- transportation of the collected waste and recyclables to processing and disposal facilities.

The direct impacts of this process contain the:

- traffic emissions deriving from the necessary transports,

- the economic costs covering the costs for personnel, truck fleet (purchase and maintenance costs), fuel cost etc., and

- some social impacts with regard to the social acceptability, equity and function of the Collection and Transportation management in the waste management system. 
Within the developed Assessment Tool the following waste Treatment processes have been modelled:

- composting of separately collected organic waste

- digestion of separately collected organic waste

- aerobic mechanical-biological pre-treatment (MBP) of mixed/ residual waste

- anaerobic MBP of mixed/residual waste

- incineration with energy recovery of mixed/residual waste

- landfilling of mixed/residual waste

- recycling of separately collected materials: paper and cardboard, glass, metals, plastics, packaging waste, mixed dry recyclables (MDR) and waste electric and electronic equipment (WEEE).

The technologies selected for modeling are the ones most commonly used in modern waste management systems in Europe. They are considered as state-of-the-art, but already broadly verified treatment methods.

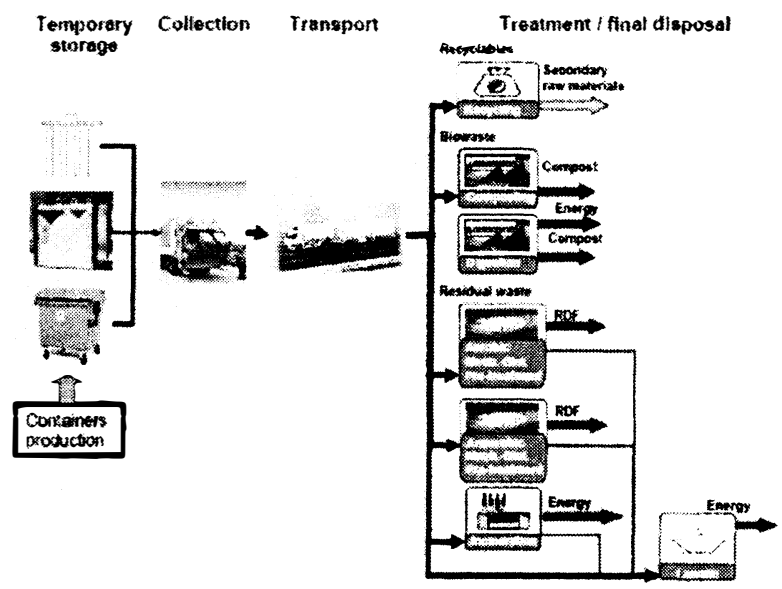

Figure 2. Waste management sub-system

\section{SUSTAINABILITY ASSESSMENT}

There are three integral part of sustainability in waste management: environmental, economic and social sustainability.

One of the broadly recognised definitions of environmental sustainability is the one provided by Goodland after Daly [2]: 


\section{Kalmar ECO-TECH '05 and \\ The Second Baltic Symposium on Environmental Chemistry \\ KALMAR, SWEDEN, November 28-30, 2005}

"Environmental sustainability itself seeks to improve human welfare by protecting the sources of raw materials used for human needs, and ensuring that the sinks for human wastes are not exceeded, in order to prevent harm to humans.e(...) On the sink side, this translates into keeping emissions within the assimilative capacity of the environment without impairing it. On the source side, harvest rates of renewables must be kept within regeneration rates ..."

Based on the above provided definition of environmental sustainability, general objectives for any human activity can be summarised as an objective of rational resource consumption and reduction of environmental pollution. Hence, also Environmental Sustainability in Waste Management may be expressed through these two major objectives

- conservation of resources and

- pollution prevention [1].

In order to compare the magnitude of the impacts in the different categories, the characterised results have been normalised. In the normalisation step, the results are related to the overall environmental impacts in a certain region for a certain year. Thus the results can be described in e.g. Inhabitant Equivalents. One inhabitant equivalent represents the total impact in a certain environmental assessment category of a certain geographical region within one year divided by the number of inhabitants within that region in the considered year. In this way the following LCA impact categories have been determined as relevant for assessment of waste management scenarios:

- depletion of abiotic resources

- climate change

- human toxicity

- photo-oxidant formation

- acidification

- eutrophication.

Economic sustainability is related (and refers) to a specific technical - organizational system, a specific time horizon and a specific decision maker. A system operates in an economically sustainable manner if it covers all its expenses and it expects to do so over the horizon of the analysis. If the system covers part of its expenses through subsidies, it could be considered sustainable only if there is a guarantee that these subsidies will continue to be available "forever".

Economic sustainability also implies the least expensive waste management system provided that it secures sufficient revenues to ensure

- an economically sound and continuous operation as well as

- coverage of all aftercare expenses for a period stipulated by law (certainly not less than 30 years after closure) [1].

One should underline the difficulty in defining the same boundaries for the analysis for all three pillars of sustainability. In economics, one would rather easily identify costs and benefits related to the municipality and could separate them from those affecting neighbouring geographic areas. 


\section{Kalmar ECO-TECH '05 and \\ The Second Baltic Symposium on Environmental Chemistry \\ KALMAR, SWEDEN, November 28-30, 2005}

This is not the case for environmental impacts. The municipality is mainly interested in economic and social aspects, rather than in more vague and beyond-its-control problems like global warming (the municipality can not be held "responsible" for poor environmental performance, when it has no control over the design and the environmental performance of the collection vehicle.)

The economic sustainability criteria are grouped as follows:

- efficiency at both the sub-system level and the system level

- equity

- dependence on subsidies

Social Sustainability in Waste Management (SoSWM) is an integral part of sustainability in waste management, the other parts are environmental and economic sustainability. SoSWM, in broad terms, is the ethical behaviour of a waste management system towards society. In particular, this means planning and managing municipal waste responsibly towards society which has a legitimate interest in this issue and not just accomplishing legislation.

Priority aspects that should be considered in SoSWM:

- citizens' rights and obligations

- employee rights and obligations

- services suppliers' responsibilities

- government or controlling authority responsibilities

- social and environmental protection

- community involvement [1]

These "priorities" are considered from three different social sustainability perspectives:

- social acceptability (MSWMS must be acceptable)

- social equity (equitable distribution of MSWMS benefits and detriments between citizens)

- social function (social benefit of MSWMS)

A list of "relevant" criteria and indicators for measuring social sustainability, classified under the next three different stages of MSWMS chain, is presented:

1.- Temporary Storage

2.- Collection System and Transport

3.- Waste Treatment

Table 1 shows the social criteria and indicators taken into account to measure the social sustainability of the MSWMS. This table shows the social perspective those measures, and the MSWMS stage that assesses each indicator. 
Kalmar ECO-TECH '05 and

The Second Baltic Symposium on Environmental Chemistry

KALMAR, SWEDEN, November 28-30, 2005

Table 1. List of the social criteria and indicators.

\begin{tabular}{cccc}
\hline Social Acceptability & Temporary Storage & Collection Transport & Treatment \\
\hline Odour & Yes & No & Yes \\
Visual impact & Yes & No & Yes \\
Convenience & Yes & No & No \\
Urban space & Yes & No & Yes \\
Private space & Yes & No & No \\
Noise & Yes & Yes & Yes \\
Complexity & Yes & No & No \\
Traffic & No & Yes & Yes \\
Risk perception & No & No & Yes \\
\hline Social Equity & & & No \\
\hline Distribution/Location & Yes & No & Yes \\
Employment quality & No & Yes & Yes \\
\hline Social function & & No & Yes \\
\hline Recycling/Destination & No & Yes & \\
Employment quantity & No & & \\
\hline
\end{tabular}

\section{SUMMARY OF RESULTS OF CASE STUDIES}

Four to five alternative waste management scenarios, reflecting various situations and predictions of the waste management were developed for each of five European cities in close collaboration with the local municipality representatives. One scenario (generally No. 1 but in Reus No. 3) characterises the present situation, while the other three or four analyse some possible developments (characterised by different solutions of Temporary Storage, Collection, Transport and Treatment). Obviously, there are also many other potential alternatives in each case, not presented here due to limited time of project, which should be assessed using developed tools in order to find the best solution. These could be done during further studies and analyses by the municipalities. Presented results of case studies show the wide range of different potential solutions and demonstrate possibilities of the tools to assess them.

It is a really difficult task to compare among all the scenarios analysed because there are some differences in attempts, quantities of waste managed and many other details. But from the other side all contributors were using the same methodology and Tools developed, which lead generally to a certain unification of case studies. In Table 2 are shown the numbers of inhabitants and produced waste amount.

Table 2. The city description.

\begin{tabular}{ccccc}
\hline City & Country & Scenarios marking & Population & $\begin{array}{c}\text { Waste amount generated in household } \\
\text { on assessment year, } \mathrm{t}\end{array}$ \\
\hline Xanthi & Greece & $\mathrm{X} 1, \ldots, \mathrm{X} 5$ & 102.000 & 15.305 \\
Kaunas & Lithuania & $\mathrm{K} 1, \ldots, \mathrm{K} 4$ & 374000 & 151.687 \\
Wroclaw & Poland & $\mathrm{W} 1, \ldots, \mathrm{W} 4$ & 640000 & 308.200 \\
Nitra & Slovakia & $\mathrm{N} 1, \ldots, \mathrm{N} 2$ & 87000 & 41.657 \\
Reus & Spain & $\mathrm{R} 1, \ldots, \mathrm{R} 2$ & 98000 & 56.651 \\
\hline
\end{tabular}




\section{Kalmar ECO-TECH '05 and \\ The Second Baltic Symposium on Environmental Chemistry \\ KALMAR, SWEDEN, November 28-30, 2005}

The present waste management of the target cities, except Reus, is characterised by the relatively low level of recycling and recovery of materials as well as by a lack or small extent of residual waste treatment before landfilling. Reus, with implemented recycling, composting and incineration of waste, presents a relatively high level of waste management development.

Results of case studies done for all target cities have shown that proposed modernisation of existing waste management systems will generally enta:l environmental relief and improving social acceptance of future waste management scenarios in comparison to the present situation. This conclusion is not fully valid for Reus where adding of MBP to existing system will result in a slight decrease in social acceptability of the proposed waste management system. However, improvement of waste management system needs investments in waste treatment facilities and increased costs of operation for these facilities.

In Table 3 are described the chosen scenarios. There is shown, collect the city the fraction separate or not, what treatment way is chosen.

In each study the most simple waste management system (landfilling of untreated waste as main disposal option) is portrayed in reference scenario 1 (in all cities except Reus this is the present system), while the other scenarios contain different solutions of waste collection, transport and treatment. Generally, the extent of separate collection of materials, levels of recovery as well as degrees of waste transformation before landfilling increase with growing scenario number (from 2 to 4 or 5 (Xanthi)).

\section{THE RELATIVE GLOBAL IMPACT OF SCENARIOS IN CITIES}

In Figures 3-7 the relative global impact is presented for all scenarios of each city. It evaluates the impact of scenarios relative to scenario 1. Because of this, the relative global impact for scenario 1 is equal to 100 . In case of the environmental impacts this value may also be -100 , which represents an environmental gain. Economic and social indicators only show positive results.

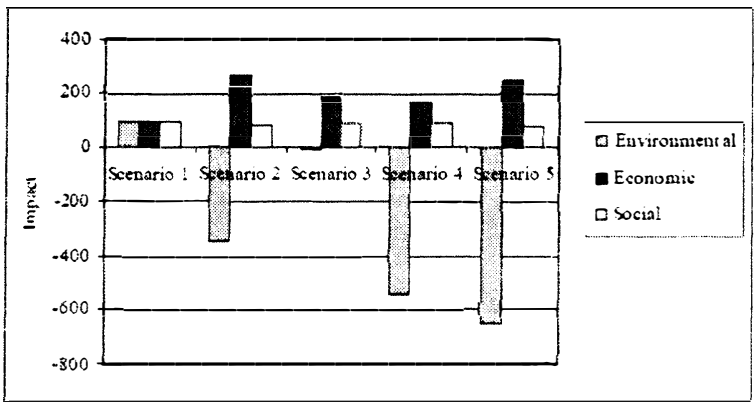

Figure 3. Relative Impacts on sustainability of MSWMS scenarios for Xanthi. 
Table 3. The descriptions of chosen Scenarios in Cities

\begin{tabular}{|c|c|c|c|c|c|c|c|c|c|c|c|c|c|c|}
\hline \multirow{2}{*}{$\begin{array}{c}\text { City, } \\
\text { Scenario } \\
\text { No. }\end{array}$} & \multirow[t]{2}{*}{$\mathrm{TS}^{\prime}$} & \multicolumn{7}{|c|}{ Separate collection } & \multicolumn{6}{|c|}{ Residual and MDR waste treatment after collection } \\
\hline & & Glass & Metals & Paper & Plastics & WEEE $^{2}$ & $\begin{array}{c}\text { Bio- } \\
\text { waste }\end{array}$ & $\mathrm{MDR}^{3}$ & $\mathrm{ANMBP}^{4}$ & $\mathrm{AEMBP}^{5}$ & Composting & Incineration & Landfill & $\begin{array}{c}\text { MDR } \\
\text { sorting }\end{array}$ \\
\hline $\mathrm{Xl}$ & - & - & - & - & - & - & - & - & - & - & - & - & $100 \%$ & - \\
\hline $\mathrm{X} 2$ & - & - & - & - & - & - & - & - & - & - & - & $100 \%$ & - & - \\
\hline $\mathrm{X} 3$ & - & - & - & - & - & - & + & - & $31,23 \%$ & - & - & - & $68,77 \%$ & - \\
\hline $\mathrm{X} 4$ & - & - & - & - & - & - & - & + & - & - & - & - & $65,04 \%$ & $34,96 \%$ \\
\hline $\mathrm{X} 5$ & - & - & - & - & - & - & + & + & $31,23 \%$ & - & - & - & $33,81 \%$ & $34,96 \%$ \\
\hline $\mathrm{Kl}$ & + & + & + & + & + & + & - & - & - & - & - & - & $100 \%$ & - \\
\hline $\mathrm{K} 2$ & + & + & + & + & + & + & - & - & - & - & - & - & $100 \%$ & - \\
\hline K3 & + & + & + & + & + & + & - & - & - & $100 \%$ & - & - & - & - \\
\hline K4 & + & + & + & + & + & + & - & - & - & $100 \%$ & - & $\begin{array}{c}\text { after } \\
\text { ANMBP }\end{array}$ & - & - \\
\hline W1 & - & + & + & + & + & - & - & - & - & - & - & - & $100 \%$ & - \\
\hline W2 & - & + & - & - & - & + & - & + & - & $80,26 \%$ & - & - & - & $19,74 \%$ \\
\hline W3 & - & + & + & + & + & + & + & - & - & $79,67 \%$ & $20,33 \%$ & - & - & - \\
\hline W4 & + & + & - & - & - & + & + & + & - & - & $16,28 \%$ & $64,48 \%$ & - & $19,24 \%$ \\
\hline $\mathrm{Nl}$ & + & + & - & + & + & - & + & - & - & - & $4,87 \%$ & - & $95,13 \%$ & - \\
\hline N2 & + & + & + & + & + & - & - & - & - & $100 \%$ & - & $\begin{array}{c}\text { after } \\
\text { ANMBP }\end{array}$ & - & - \\
\hline N3 & + & - & - & - & - & - & + & + & - & $82,48 \%$ & $4,09 \%$ & - & - & $13,34 \%$ \\
\hline N4 & + & + & + & + & + & + & + & - & - & $100 \%$ & - & - & - & - \\
\hline $\mathrm{Rl}$ & - & - & - & - & - & - & - & - & - & - & - & - & $100 \%$ & - \\
\hline $\mathrm{R} 2$ & - & + & + & + & + & + & - & - & - & - & - & $100 \%$ & - & - \\
\hline R3 & - & + & + & + & + & + & + & - & - & - & $11,91 \%$ & $88,09 \%$ & - & - \\
\hline R4 & - & + & + & + & + & + & + & - & - & $16,17 \%$ & $11,58 \%$ & $72,25 \%$ & - & - \\
\hline
\end{tabular}

1-Transfer Station

2 - Waste from Electrical and Electronic Equipment

3 - Mixed Dry Recyclables

4 - Anaerobic Mechanical - Biological Pre-Treatment

5 - Aerobic Mechanical - Biological Pre-Treatment 
Kalmar ECO-TECH '05 and

The Second Baltic Symposium on Environmental Chemistry KALMAR, SWEDEN, November 28-30, 2005

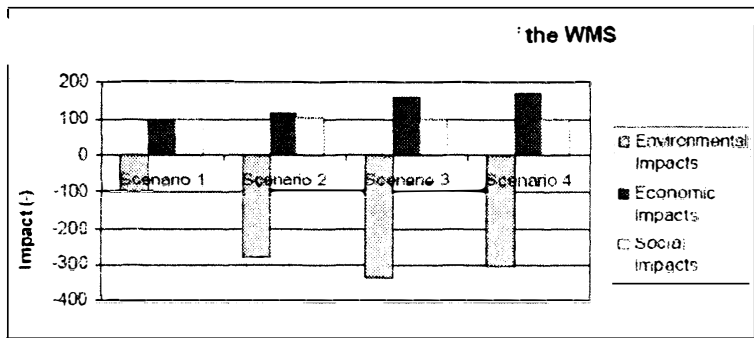

Figure 4. Relative Impacts on sustainability of MSWMS scenarios for Kaunas.

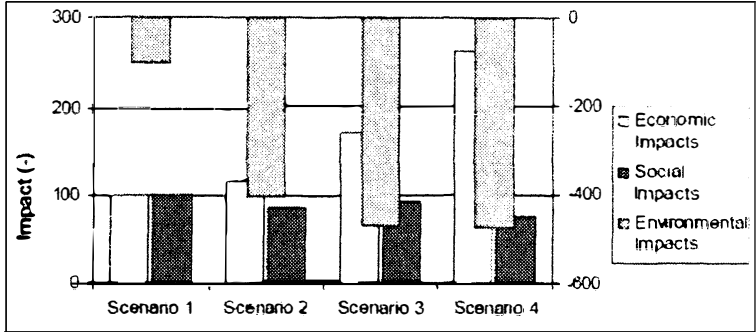

Figure 5. Relative Impacts on sustainability of MSWMS scenarios for Wroclaw.

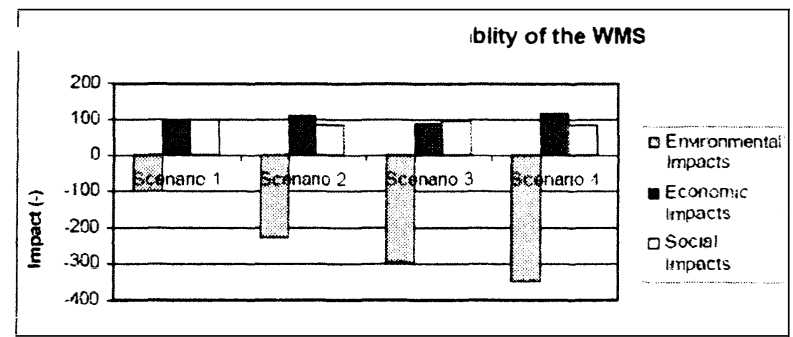

Figure 6. Relative Impacts on sustainability of $M S W M S$ scenarios for Nitra. 


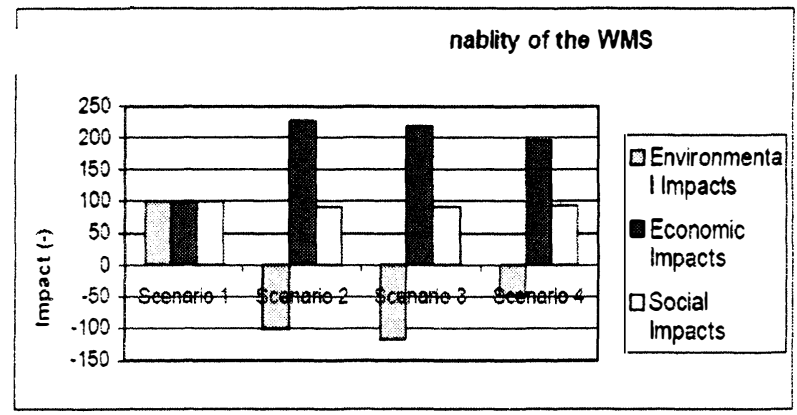

Figure 7. Relative Impacts on sustainability of MSWMS scenarios for Nitra

\section{THE CONCLUDING RESULTS FROM THE USING OF LCA-IWM ASSESSMENT TOOL}

Kaunas. Since May 2004 Lithuania is a member of the EU. Accordingly the best scenario had to be chosen in accordance with EU legislation. The European Commission has determined a number of specific recovery and recycling targets to be achieved by various target years. The current situation (Scenario 1) does not comply with these targets at all. This means that the current situation has to be improved. Scenarios 3 and 4 are in compliance with targets for recovery and recycling of packaging waste as well as with targets for diversion of biodegradable waste from landfilling. In the case of Kaunas city, the most important environmental indicators are global warming, acidification and human toxicity. Regarding these three indicators, the worst scenario is Scenario 1. The Scenarios 3 and 4 show good results in reducing "global warming" and "acidification" (environmental relief), but they also show relatively small environmental burden in impact category "human toxicity".

There is a big difference between investment costs of the scenarios. The investments are $€ 16 \mathrm{mio}$ higher in Scenario 3 (for MBP facility) and $€ 20$ mio higher (for MBP and Incineration facilities) in Scenario 4 comparing with Scenario 1.

The annual total cost of Waste Management System vary from 56,16 Euro/t (60,24 Euro/hh, 22,98 €/person) in Scenario 1 to 93,61 Euro/t (100,39 €/hh, 38,30 €/person) in Scenario 4.

The revenue from recovered material and energy vary from $€ 1.676 .680$ (Scenario 1) to $€ 3.396 .760$ (Scenario 4).

Relative global impacts of scenarios were compared (they are related to baseline Scenario 1). Social criteria show much lower impacts of Scenarios 3 and 4 on social sustainability of Waste Management System.

Comparing the above mentioned impacts on environmental, economic and social sustainability of Waste Management System, Scenario 3 is recommended as the best. Scenario 4 seems to be not 


\section{Kalmar ECO-TECH '05 and \\ The Second Baltic Symposium on Environmental Chemistry \\ KALMAR, SWEDEN, November 28-30, 2005}

realistic due to the very small capacity of incineration plant treating only combustible residues of MBP. There is a need for analysing additional waste treatment options for Kaunas using the developed tool, like incineration of whole waste stream as only treatment option. The composting will be hardly implementable because of the citizen's aversion to separate kitchen waste. According to results of performed studies people are ready to collect plastic and hazardous waste separately.

Wroclaw. Base scenario 1, containing the present situation of waste management in Wroclaw, was compared with three possible scenarios of future Wroclaw's MSWMS. Different ways of treatment of main residual waste streams (aerobic MBP or incineration) and different ways of separate collection were proposed. The comparison of environmental impacts of subsystems, in particular scenarios, shows that waste treatment in scenario I (present situation) causes the absolutely highest environmental burden (in the impact category global warming) among all impact categories in all scenarios. The environmental burdens of other MSWMS stages in scenarios 2-4 are rather low in comparison to that one above mentioned.

Condensed comparison of impacts of scenarios on sustainability of MSWMS was made. Relative impacts of scenario 1 are given a value of $100 \%$, to which the other scenarios are compared. Intensified extent of waste treatment (and minimizing waste landfilling) leads to overall growing environmental relief in scenarios 2 to 4 (negative impacts). It means that credits from recovery of materials and energy, even in present situation of MSWMS, surpass environmental burdens of some subsystems. Only impact categories eutrophication and human toxicity show relatively small environmental burden in some scenarios. Scenario 4 entails the highest environmetal relief among all scenarios assessed.

Economic and social impacts take positive values. Investment costs of MSWMS proposed in scenario 2 are ca. $15 \%$ bigger than the costs of the present system (scenario 1), while investments proposed in scenario 3 and 4 are ca. $70 \%$ and almost three times more expensive in comparison to scenario 1 , respectively.

Annual cost of MSWMS in scenario 2 is ca. $50 \%$, in scenario 2 - ca. $66 \%$ and in scenario 4 - ca. $84 \%$ higher than at present (scenario 1). All proposed scenarios should be socially acceptable. Scenarios 2-4 are characterised by improved social perception of MSWMS.

\section{All scenarios of future MSWMS achieve targets of Landfill and Packaging Directives.}

Comparing relative impacts of all proposed scenarios, scenario 3 seems to combine relatively high environmental profits with moderate costs and high social acceptability. Scenario 4, containing incineration, is even little more socially accepted, but provides better environmental profits, but require double the investment.

Nitra. Baseline scenario 1, describing the present situation of waste management in Nitra. was compared with three possible scenarios of future Nitra's MSWMS. Different ways of treatment of main waste stream (aerobic MBP or incineration) and various alternatives of separate collection were proposed. 


\author{
Kalmar ECO-TECH '05 and \\ The Second Baltic Symposium on Environmental Chemistry \\ KALMAR, SWEDEN, November 28-30, 2005
}

Comparison of environmental impacts of MSWMS stages shows that Temporary Storage and Collection \& Transport contribute mainly to the impact categories: abiotic depletion, global warming, photooxidant formation and acidification while treatment stage influences only human toxity and eutrophication. This observation concerns new scenarios 2-4. Because of credits allocated to the treatment stage of MSWMS (recovery of materials and energy) there is visible environmental relief concerning impact categories abiotic depletion and acidifiction in all scenarios (1-4), global warming in scenarios 3 and 4 as well as photo-oxidant formation in scenarios 2-4. Total relative environmental impacts for each scenario assessed take negative values what means that positive aspects of material and energy recovery in treatment stage, even in present waste management situation, surpass environmental burdens. In this respect the most advantageous is scenario 4 .

Economic and social relative impacts take positive values. In comparison to scenario 1, all proposed new scenarios 2-4 present better social acceptability, especially scenarios 2 and 4 . However, development of scenarios 2 and 4 entails higher economic impacts in comparison to scenario 1 while scenario 3 is even more effective economically than the present situation (scenario 1).

Taking into account all relative impacts of scenarios on sustainability of MSWMS it is visible that scenario 3 combines relatively high environmental profits with the lowest costs and high social acceptability. It is recommended for implementation.

Reus. In this case study slightly different attempt was used while defining scenarios to be assessed and compared. The reason for that was actual waste management strategy of the municipality of Reus (Scenario 3) which, unlike opposition to other cities, is quite advanced and well implemented. Thus it was decided to define two scenarios which would represent past situations and another one looking into a hypothetic future. The two scenarios reflecting past situations were very different one to another and the fourth one was not much different to the actual one.

As in all modelling cases, results should be looked at carefully, because they will be as accurate as input data of the model and also because they will be more realistic the closer the model is to reality. In this case, the amount and variety of input data needed coupled with a very complex model, make the interpretation of the results a very tough task.

Having said that and looking into the assessment tools graphs it can be concluded that:

- Scenario 1 (only landfilling of untreated waste) shows a very clear different behaviour with regard to environmental, social and economic impacts, since the definition of this scenario is clearly different to the others. This concept of waste management entails environmental burden (environmental impact is positive) while the economic impact is lower than that of the other scenarios (relatively low cost of simple landfilling of waste),

- Scenarios 2 and 3 show very similar values for their environmental, economic and social indicators but scenario 3 (actual situation of waste management) is slightly more advantageous taking into account all impact categories, 
- Further development of waste management from scenario 3 to scenario 4 entails improvement of sustainability of waste management with regard to environmental and economic impact categories but this concept could be socially less accepted.

None of the scenarios assessed ensure achieving desired recycling rates of packaging waste - this remark concerns each material flow as well as overall recycling of packaging waste. Overall recovery rate of packaging waste have been achieved in scenarios 2-4 due to energy recovery during incineration of residual municipal waste.

\section{REFERENCES}

[1] den Boer, E., den Boer, J., Jager, J., (Eds), 2005. Waste management planning and optimisation. Ibidem-Verlag Stuttgart, Germany.

[2] Goodland, R., 2002. Sustainability: Human, Social, Economic and Environmental. In: Encyclopedia of Global Environmental Change, John Wiley \& Sons.

[3] Zickiene, S., Ruskus, J., 2001. Individualaus buitiniu atlieku tvarkymo modeliai: apklausos rastu duomenys. In: Environmental research, engineering and management, 2001. No.4 (18), Kaunas, pp. 19-29, 